Disponível em

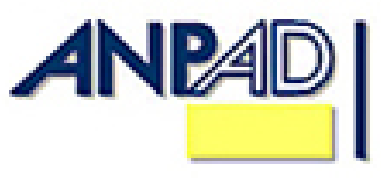

http://www.anpad.org.br/rac

RAC, Rio de Janeiro, v. 19, n. 6, art. 6, pp. 772-794, Nov./Dez. 2015

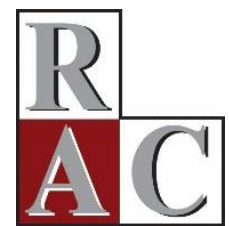

\title{
Estilo de Liderança, Controle Gerencial e Inovação: Papel das Alavancas de Controle
}

Leadership Style, Management Control and Innovation: The Role of Control Levers

Ana Paula Capuano da Cruz

Universidade Federal do Rio Grande - FURG

Fábio Frezatti

Universidade de São Paulo - USP

Diógenes de Souza Bido Universidade Presbiteriana Mackenzie - Mackenzie

Artigo recebido em 26.11.2014. Última versão recebida em 04.05.2015. Aprovado em 20.05.2015. 


\title{
Resumo
}

Fundamentado nas lideranças transformacional e transacional (Bass, 2008) e no modelo de alavancas de controle de Simons (1995), este estudo explora o estilo de liderança como um antecedente da definição de uso do sistema de controle gerencial (SCG) e o papel de seus diferentes tipos de uso na inovação tecnológica. A pesquisa foi operacionalizada por meio de um levantamento com 164 empresas, e os dados foram tratados com emprego da técnica de modelagem de equações estruturais. A liderança transformacional foi comprovada como um antecedente do uso interativo do SCG e do sistema de crenças. Os sistemas de crenças, interativo e de restrições, influencia positivamente a inovação tecnológica. Significa que as empresas que buscam inovar em seus produtos e processos devem investir: (a) na comunicação de valores e nos objetivos relacionados à inovação; (b) em discussões que envolvam diferentes áreas e membros do negócio, considerando inclusive a possibilidade de interagir com agentes externos à empresa; e, ainda, (c) no estabelecimento de limites que especifiquem um campo de ação para os colaboradores, fornecendo foco e gerando condições para que as ações pretendidas sejam desenvolvidas. Esta pesquisa expande o conhecimento sobre SCG indicando suas formas de uso para promover a inovação e obter renovação estratégica.

Palavras-chave: estilo de liderança; sistema de controle gerencial; inovação tecnológica; alavancas de controle.

\begin{abstract}
Based on transformational and transactional leadership (Bass, 2008) and on the Simons' (1995) levers of control model, this study explores leadership style as an antecedent of the definition of management control system (MCS) use and the role of its different usage types in technological innovation. The research was operationalized by a survey of 164 companies and data were analyzed using structural equation modeling. Transformational leadership was confirmed as an antecedent of the interactive use of MCS and beliefs systems. Belief, interactive and boundary systems positively influence technological innovation. This means that organizations seeking to innovate in products and processes should invest in: (a) the communication of values and goals related to innovation, (b) discussions involving different areas and members of the business, including considering the possibility of interaction with external agents, and also (c) the establishment of boundaries that specify a field of action for employees, providing focus and creating conditions for development of intended actions. This research expands the knowledge about management control, indicating the ways in which organizations use their MCS to promote innovation and obtain strategic renewal.
\end{abstract}

Key words: leadership style; management control system; technological innovation; levers of control. 


\section{Introdução}

Em ambientes cada vez mais desafiadores, a inovação representa uma alternativa para que as organizações mantenham ou incrementem sua eficiência (West \& Anderson, 1996), representando, assim, um elemento crítico para viabilizar suas competitividade e continuidade (Armbruster, Bikfalvi, Kinkel, \& Lay, 2008; Damanpour, Szabat, \& Evan, 1989; Gumusluoglu \& Ilsev, 2009).

Estudos nacionais recentes comprovam a ausência de mecanismos de controle ligados ao processo de inovação, o que pode provocar entendimentos inadequados nas organizações brasileiras, implicando manutenção, postergação e, em alguns casos, abandono de projetos de inovação (Frezatti, Bido, Cruz, \& Machado, 2014; Nisiyama \& Oyadomari, 2012). Ainda sobre o ambiente nacional, tem-se comprovado que as pessoas são atores relevantes para obtenção de êxito nos processos de inovação (Souza \& Bruno-Faria, 2013).

Em função desse contexto, a busca pela identificação de fatores que possam estimular a promoção de respostas aos desafios ligados ao incremento da eficiência empresarial ganha eco nos meios profissional e acadêmico, uma vez que, especialmente nessa última via, podem-se obter subsídios para direcionar o planejamento de ações orientadas para manutenção de uma organização em um ambiente em que se valorizam atividades de inovação.

Em meio à amplitude do campo de estudo sobre inovação - fatores envolvidos, tais como novas ideias, pessoas, contextos e transações (Van de Ven, 1986); inovação como processo (Freeman, 1995); difusão e adoção de inovação; innovating e innovativeness (Damanpour, 1991), entre outros encaminhamentos - destaca-se a inovação tecnológica, que, no cenário brasileiro, tem se desenvolvido em ritmo bastante acelerado.

Pensar na gestão de empresas que têm expressivos desafios de gestão ligados à inovação remete ao controle gerencial - atividade chave para a gestão das organizações. O controle gerencial direciona o foco para tarefas que auxiliam na manutenção da coerência operacional de uma empresa como um todo, permitindo que ela possa perpetuar a sua existência (Otley, 1994). Para que esse direcionamento esperado se materialize, as organizações devem desenvolver um modelo de sistema de controle gerencial (SCG) que atenda às suas necessidades (Otley, 1994), e a formatação de um sistema estruturado envolve inúmeras tomadas de decisões, de modo que as organizações devem reunir esforços para, regularmente, desenvolver/definir um sistema de informações dinâmico.

No entanto, apesar de haver relativo consenso acerca da necessidade de considerar aspectos como atualidade, flexibilidade, amplitude, diversificação etc. no processo de estruturação de um SCG, Abernethy, Bouwens, e Lent (2010) destacam que gestores podem seguir diferentes caminhos para definir e dar publicidade à visão da organização, além de adotar diferentes abordagens de comunicação e, inclusive, efetuar escolhas de controle e monitoramento em função de uma abordagem individual específica.

Essas diferenças acerca da forma de conduzir os processos são explicadas pela personalidade e por características comportamentais dos gestores que podem ser tratadas como estilo de liderança (Abernethy, Bouwens, \& Lent, 2010). Diante do exposto, esta pesquisa busca responder: Como o estilo de liderança influencia a definição de uso do sistema de controle gerencial e a inovação tecnológica? O objetivo central consiste em compreender, a partir do perfil de representantes da diretoria de empresas listadas na edição Melhores \& Maiores 2012, como o estilo de liderança influencia a definição de uso de SCG e como este impacta o processo de inovação nessas organizações.

O fenômeno da inovação é de extrema relevância para a sustentabilidade das organizações, pois permite a sua sustentação tanto em termos de novos produtos, processos mais eficientes e baratos ou mesmo empresas mais aderentes às necessidades do ambiente. A infraestrutura que uma organização dispõe para inovação é fundamental para o seu sucesso e pode ser encontrada de diferentes maneiras ou complexidades. Estudos como o de Vaccaro, Jansen, Bosch e Volberda (2012) comprovam que a 
inovação tem emergido sem uma base referencial específica nas organizações. Ainda que os resultados de pesquisas internacionais apresentem resultados difusos (Nisiyama \& Oyadomari, 2012), existem evidências de que a inovação tem sido prejudicada pela falta de uma estrutura formal que possibilite o amadurecimento das atividades dessa natureza, ou seja, as organizações precisam de controles e indicadores de inovação para que possam avaliar suas atividades (Frezatti et al., 2014; Vaccaro, Jansen, Bosch, \& Volberda, 2012).

De forma complementar, características comportamentais dos atores envolvidos no processo de gestão têm papel crucial na determinação da inovação organizacional (Cummings, 1965). Ainda que pesquisas sobre controle gerencial e liderança (Abernethy et al., 2010; Jansen, 2011), inovação e liderança (Alsalami, Behery, \& Abdullah, 2014; García-Morales, Jiménez-Barrionuevo, \& GutiérrezGutiérrez, 2012; Gumusluoglu \& Ilsev, 2009) e controle gerencial e inovação (Arjaliès \& Mundy, 2013; Bisbe \& Malagueño, 2009; Chong \& Mahama, 2014) tenham se intensificado nos últimos anos, o tratamento conjunto desses três constructos (liderança, controle gerencial e inovação) ainda representa uma lacuna no ambiente de pesquisa científica. Desse modo, este estudo proporciona contribuições relevantes, no sentido de integrar dois constructos (estilo de liderança e controle gerencial) cujo efeito na inovação já foi empiricamente comprovado, porém de forma não integrada.

Este artigo está estruturado da seguinte forma: complementarmente à introdução, tem-se a fundamentação teórica, que serviu de base para o desenvolvimento das hipóteses. A seguir são descritos os procedimentos metodológicos empregados na condução da pesquisa. Os resultados são discutidos na sequência e, por fim, expõem-se as conclusões do estudo.

\section{Fundamentação Teórica}

A fundamentação teórica desta pesquisa reúne: (a) estilo de liderança; (b) sistema de controle gerencial; e (c) inovação tecnológica.

\section{Estilo de liderança}

Para o desenvolvimento deste estudo, foram delimitadas as lideranças transformacional e transacional, o que se justifica pelo fato de a liderança transformacional ser apontada como uma das mais influentes teorias contemporâneas de liderança (Hu, Wang, Liden, \& Sun, 2012), bem como pela afinidade que o tema exibe com a inovação.

A liderança transformacional é caracterizada por uma forte carga de motivação e aproximação entre líderes e liderados (Calaça \& Vizeu, 2015). Segundo os autores, a proposta da liderança transformacional considera

que o ato de liderar envolve a criação de novos líderes a partir das pessoas que estão ao redor, envolvendo-as não apenas com as tarefas rotineiras, mas dando às mesmas, além de reconhecimento, perspectivas e condições de desenvolvimento da capacidade de tomada de decisão (Calaça \& Vizeu, p. 127).

Líderes transformacionais motivam seus seguidores e conseguem fazer com que trabalhem além do que originalmente estavam destinados a trabalhar, são proativos e buscam sensibilizar seus seguidores da importância de alcançar os objetivos previstos (interesses coletivos) (Antonakis, Avolio, \& Sivasubramaniam, 2003; Bass, 2008). Este estilo é constituído por quatro classes de comportamento (Hu et al., 2012) e se refere aos comportamentos gerenciais que transformam os liderados e os inspiram a irem além de suas expectativas, transcendendo o interesse pessoal pelo bem da organização.

A (a) influência idealizada é um elemento que reforça o engajamento em comportamentos que nutrem uma relação de confiança e identificação com o líder e diz respeito à capacidade de influenciar 
seguidores por meio de um ideal (Hu et al., 2012). A (b) motivação inspiradora está ligada a uma visão de futuro. Os líderes provêm significado e desafiam o trabalho de seus seguidores, despertando o espírito de time que é nutrido pelo seu otimismo e entusiasmo em relação ao futuro que projeta (Bass \& Riggio, 2005). A (c) estimulação intelectual refere-se à capacidade de provocar reflexão e fazer com que um indivíduo vá além de sua própria visão das coisas (Vizeu, 2011); é uma espécie de desafio ao status quo (Hu et al., 2012). A (d) consideração individualizada refere-se ao desenvolvimento e ao crescimento individuais, pois o líder dispensa atenção individualizada aos seus seguidores no processo de busca por desafios e promoção de autodesenvolvimento (Vizeu, 2011).

A liderança transacional tem a finalidade de estimular o alcance do nível de desempenho desejado/negociado (Howell \& Avolio, 1993). Esse tipo de líder condiciona a obtenção de recompensas à conclusão satisfatória do que foi acordado (Bass \& Riggio, 2005). O líder transacional estabelece um processo de trocas com base no cumprimento de obrigações e não individualiza as necessidades de seus subordinados, nem mesmo está preocupado com o desenvolvimento pessoal de seus seguidores (Northouse, 2009). A liderança transacional é constituída por três fatores (Bass, 2008).

A (a) recompensa contingente é uma transação construtiva (Bass, 2008) que se refere aos comportamentos do líder focados em esclarecer o papel e as exigências da tarefa (Antonakis et al., 2003). O esforço dos seguidores é trocado por recompensas especificadas (Northouse, 2009). A gestão por exceção é uma transação corretiva (Bass, 2008). Na (b) gestão por exceção ativa, tem-se ativa vigilância do líder com o objetivo de assegurar o cumprimento das normas; e na (c) gestão por exceção passiva, o líder espera que algo dê errado para então tomar alguma atitude (Bass \& Riggio, 2005).

\section{Sistema de controle gerencial}

Esta investigação explora a dimensão uso do SCG, com base no modelo de alavancas de controle de Simons (1990, 1991, 1995), que tem sido largamente utilizado em pesquisas da área de controle gerencial (Abernethy \& Brownell, 1999; Bisbe \& Malagueño, 2009; Bisbe \& Otley, 2004; Harlez \& Malagueño, in press; Sánchez, López-Valeiras, Rodríguez-González, \& Feliu, 2013; Widener, 2007).

Para Simons (1995), uma estrutura específica de quadro alavancas proporciona o controle estratégico das organizações, e a forma como os gestores utilizam esses sistemas é fundamental à empresa. As alavancas de controle representam quatro diferentes modos de uso para o SCG, e os gestores devem buscar seu uso integrado e balanceado para colocar a estratégia em prática e, ainda, para monitorá-la (Simons, 1995). O autor propõe o uso de controles positivos, formatados para encorajar a busca por novas oportunidades (sistemas de crenças e interativo) e negativos, para restringir essa busca de modo que a empresa não se desvie do foco principal (sistemas de restrições e diagnóstico).

O sistema de crenças é usado para inspirar e direcionar a busca por novas oportunidades. Representa um conjunto explícito de definições que indicam os valores que a organização pretende que sejam adotados pelos colaboradores, bem como a direção que devem seguir. Espera-se que os gerentes comuniquem e reforcem, formal e sistematicamente, essas definições aos seus subordinados (Simons, 1995).

O sistema interativo tem a finalidade de proporcionar o envolvimento dos gestores em decisões que envolvem atividades de seus subordinados, estimular a busca por novas oportunidades e promover aprendizagem organizacional, permitindo identificação de estratégias emergentes (Simons, 1995). É um sistema centrado no diálogo, que atua como um eixo estruturante da renovação estratégica.

O sistema de restrições estabelece limites à ação organizacional e deve ser utilizado para delinear um campo aceitável de atividades, levando em conta riscos que precisam ser evitados e, ao mesmo tempo, oportunidades que precisam ser buscadas (Simons, 1995). O sistema diagnóstico é a alavanca de controle mais tradicional, projetado para assegurar a realização de objetivos predeterminados. Produz um efeito oposto ao sistema interativo. Enquanto este encoraja a busca e o surgimento de novas ideias e experimentações, aquele trabalha para que a empresa não se desvie de seu foco (Simons, 1995). O uso diagnóstico serve para monitorar resultados obtidos e corrigir desvios daquilo que é esperado. 


\section{Inovação tecnológica}

A literatura sobre inovação é altamente dispersa e multiforme, não havendo consenso acerca de sua definição; trata-se se um constructo complexo que envolve geração, desenvolvimento e implementação de novos comportamentos ou ideias, podendo representar novos produtos, serviços, tecnologia de processos de produção, estruturas, sistema administrativo (Damanpour, 1991). No entendimento de Rogers (1995), inovação não possui uma dimensão tão ampla quanto a de Damanpour (1991), representando uma ideia ou algo que passa a ser praticado e é percebido como novo por alguém ou unidade de adoção. Em linhas gerais, as investigações sobre o tema têm gerado extensos resultados, mas as principais fontes de inovação, seus processos e seus determinantes ainda carecem de aprofundamentos (Gopalakrishnan \& Damanpour, 1997).

As inovações tecnológicas são um componente fundamental para inovação de produtos e de processos e, para efeito desta pesquisa, inovação tecnológica é tratada como um processo que envolve o desenvolvimento de novos produtos e/ou processos e alterações tecnológicas significativas em produtos e/ou processos já existentes, de modo que haja geração de algo novo ou aprimorado (Organização para a Cooperação Econômica e Desenvolvimento [OCDE], 2005), compreendendo mudanças que geram algum grau significativo de novidade para a empresa (não necessariamente para o mercado) no que diz respeito aos seus produtos e processos (OCDE, 2005).

\section{Hipóteses da Pesquisa}

Nesta seção, são desenvolvidas as hipóteses que levam em conta os estilos de liderança transformacional e transacional, as quatro alavancas de controle e a inovação tecnológica. Como o uso do SCG, é explorado sob a ótica de características comportamentais (estilo de liderança), emprega-se o termo definição para reconhecer que o uso propriamente dito é produto de uma percepção, individual ou coletiva, que, de alguma forma define, ou seja, sugere como deve se dar esse uso. Assim, nesta pesquisa, explora-se a definição de uso do sistema de controle gerencial.

\section{Estilo de liderança e definição de uso do sistema de controle gerencial}

Segundo a literatura de liderança transformacional, valores, crenças e missão da organização são relevantes para o líder transformacional, pois ele faz uso desses elementos para aumentar a motivação e o desempenho de seus seguidores (Bass, 2008; Jansen, 2011; Northouse, 2009). Esse líder esforça-se continuamente para superar quaisquer ceticismos internos e dificuldades externas, influenciando seus seguidores por meio de ideologias e valores socialmente compartilhados (influência idealizada).

Ao projetar uma visão otimista de futuro para seus subordinados (Northouse, 2009), o líder transformacional assume a função de um agente de mudanças, o que é compatível com a proposta do sistema de crenças em inspirar estratégias correntes e emergentes (Simons, 1995). Assim, desenvolvese a primeira hipótese desta pesquisa, que sugere que: a liderança transformacional influencia positivamente o sistema de crenças $\left(\mathbf{H}_{1 \mathrm{~A}}\right)$. Como o líder transformacional demonstra elevado padrão de conduta ética e moral, ele acaba servindo de modelo para seus subordinados, contribuindo para inspirar e direcionar a busca por oportunidades alinhadas aos propósitos da organização.

O sistema interativo estimula a busca por novas oportunidades (estratégias emergentes) e promove a aprendizagem organizacional (Simons, 1995). Evidências empíricas têm comprovado a associação entre liderança transformacional e aprendizagem organizacional (García-Morales et al., 2012), e esta tem sido apontada como um dos motores da liderança transformacional, pois a estimulação intelectual do líder inspira reflexões e debates (Bass, 2008) que são indispensáveis para lidar com incertezas estratégicas. Além disso, a motivação inspiradora permite que subordinados do líder transformacional sintam-se atraídos pelos estados/situações que são desejados pela organização. Desse modo, a equipe exibe uma espécie de aprovação pessoal (simpatia) quanto aos objetivos organizacionais, 
o que faz com que se sinta mais confortável e motivada para dialogar sobre as necessidades percebidas e articular a renovação estratégica proposta pelo sistema de controle interativo, sugerindo assim que: a liderança transformacional influencia positivamente o sistema de controle interativo $\left(\mathrm{H}_{1 \mathrm{~B}}\right)$.

A liderança transacional configura-se como um processo de trocas baseado no cumprimento de obrigações contratuais, ancorado em uma lógica utilitarista de recompensa financeira (Antonakis et al., 2003). O líder transacional atua em um contexto mais estático, exibe claras propostas em termos de expectativas e recompensas e mostra-se alinhado ao sistema de controle diagnóstico que fornece feedback e medidas baseadas em processos programados e em gestão por exceção (Malagueño \& Bisbe, 2010). Assim, como o sistema diagnóstico é usado para focar pesquisas e atenção da organização, limitar as chances de desvio de resultados, monitorar e recompensar o cumprimento de metas pré-estabelecidas por meio de variáveis críticas de desempenho, formula-se a seguinte hipótese de pesquisa: a liderança transacional influencia positivamente o sistema de controle diagnóstico $\left(\mathrm{H}_{2 \mathrm{~A}}\right)$.

O sistema de restrições, juntamente com o de crenças, fornece possíveis direcionamentos à organização. Ambos os sistemas informam sobre oportunidades que podem ser exploradas, criações e inovações e, enquanto o sistema de crenças motiva os colaboradores, o sistema de restrições delimita um campo de exploração (Widener, 2007). Ao restringir o espaço de exploração para assegurar o cumprimento dos objetivos, o sistema de restrições, juntamente com o diagnóstico, é um componente fundamental em termos de estrutura organizacional, que está alinhado com a ideia de gestão por exceção, uma vez que sua proposta é estimular a manutenção do status quo da empresa (Widener, 2007). Assim, espera-se que a liderança transacional influencie positivamente o sistema de restrições $\left(\mathbf{H}_{2 \mathrm{~B}}\right)$, fundamentalmente pelo fato de tal sistema ser utilizado para estabelecer, de forma explícita, os limites e as regras que devem ser respeitados (Simons, 1995).

\section{Definição de uso do sistema de controle gerencial e inovação tecnológica}

O relacionamento entre controles formais, SCG e inovação, tem sido objeto de crescente interesse na literatura (Bisbe \& Malagueño, 2009). A proposta do sistema de crenças é a de comunicar valores fundamentais da empresa e inspirar e motivar seus colaboradores a pesquisar, explorar, criar e reunir esforços engajados em ações apropriadas às aspirações da entidade (Widener, 2007).

Os achados de Souza e Bruno-Faria (2013), de que a divulgação de informações sobre inovação para todos os membros da empresa é uma prática que fomenta a inovação, reforçam a ideia de que o sistema de crenças pode contribuir para a inovação tecnológica, isso porque tal sistema representa um meio de comunicação, inspiração e motivação na organização. Como o sistema de crenças busca promover o comprometimento dos colaboradores com os objetivos da empresa e inspirá-los a buscar novas oportunidades (Arjaliès \& Mundy, 2013), desenvolve-se a hipótese de que a definição de uso do sistema de crenças influencia positivamente a inovação tecnológica $\left(\mathbf{H}_{3 \mathrm{~A}}\right)$. Espera-se influência nesta direção, uma vez que tal sistema pode ser usado para inspirar e orientar a busca de novas oportunidades a partir do fornecimento de valores básicos, propósito e direção à empresa.

Ao estimular o desenvolvimento de ideias e iniciativas, bem como a identificação de ameaças que ponham as atuais estratégias em risco, o sistema interativo gera informações relevantes para lidar com a tensão inerente ao desejo de inovar e a necessidade de realizar os objetivos propostos (Henri, 2006). Bisbe e Malagueño (2009) argumentam que o uso interativo do SCG está fortemente conectado com inovação, pois direciona a atenção organizacional para incertezas estratégicas que requerem novos conhecimentos e aprendizagem. Assim, o uso interativo cria um ambiente de diálogo que incentiva o compartilhamento de informações e o debate coletivo de como organizar e executar novos planos (Chong \& Mahama, 2014). Widener (2007) destaca que o uso interativo envolve os gestores na busca de estratégias emergentes e os auxilia a lidar com situações complexas e novas. Esse contexto que envolve novas experiências e é nutrido por curiosidade é também característico do ambiente de inovação tecnológica, sugerindo que a definição de uso do sistema de controle interativo influencia positivamente a inovação tecnológica $\left(\mathrm{H}_{3 \mathrm{~B}}\right)$. 
O uso diagnóstico concentra sua atenção na implementação das estratégias pretendidas, pois está focado na identificação de erros e desvios em relação ao que foi planejado para usá-los como feedback a fim de reorientar processos (Henri, 2006). Simons (1995) defende que a mensuração periódica de resultados obtidos e sua comparação com metas estabelecidas criam pressões que podem estimular a inovação. Tratando-se do ambiente nacional, Frezatti, Bido, Cruz e Machado (2015) analisaram perfis estratégicos e inovação, e concluíram que existe ligação entre a inovação incremental e o planejamento estratégico, e entre inovação radical e Balanced Scorecard. Assim, espera-se que, ao eliminar o peso gerado pela constante necessidade de monitoramento, a definição de uso do sistema de controle diagnóstico influencia positivamente a inovação tecnológica $\left(\mathbf{H}_{3 \mathrm{C}}\right)$. Essa hipótese sugere que, ao permitir o controle de falhas, o uso diagnóstico colabora para que os gestores possam dedicar mais tempo às outras três alavancas de controle.

O sistema de restrições, assim como o de crenças, traz consigo a proposta de estimular a procura por novas oportunidades (Widener, 2007). A autora destaca que, em ambientes dinâmicos, é necessário que algum tipo de contenção seja imposta para impedir que a organização seja envolvida em situações de alto risco, e esse é justamente o papel do sistema de restrições; um sistema que explicita limites e regras que devem ser respeitados (Simons, 1995), permitindo que os colaboradores tenham liberdade para inovar em determinadas áreas pré-definidas (Widener, 2007). Assim, espera-se que, ao demarcar fronteiras que não devem ser ultrapassadas, o sistema de restrições proporcione foco para que a inovação tecnológica seja promovida, permitindo que haja clareza sobre o campo de ação e possibilitando que sejam apresentadas inovações compatíveis com a proposta e os objetivos da empresa. Esses argumentos conduzem à última hipótese, sugestiva de que a definição de uso do sistema de restrições influencia positivamente a inovação tecnológica $\left(\mathrm{H}_{3 \mathrm{D}}\right)$.

De forma geral, a influência positiva que se espera do SCG nos processos de inovação tecnológica também tem apoio nos achados de Oyadomari, Cardoso, Silva e Perez (2010), que comprovaram a ausência de conflito entre inovação e controle em três empresas brasileiras classificadas como inovadoras na listagem do Índice Brasil de Inovação.

\section{Procedimentos Metodológicos}

Esta investigação é do tipo levantamento e foi realizada por meio de um questionário eletrônico (Apêndice), administrado com a ferramenta QuestionProß. As 1.396 empresas listadas no Anuário da Revista Exame Melhores \& Maiores, publicado em 2012, representam a população do estudo.

$\mathrm{O}$ estilo de liderança foi mensurado com base no Multifactor Leadership Questionnaire (MLQ Form 5X-Short), com a permissão da Mind Garden. O primeiro bloco do questionário buscou o levantamento de dados sobre o Estilo de Liderança do respondente e foi constituído das 32 assertivas que constam no MLQ. A definição de uso do SCG considera quatro variáveis latentes, que são os sistemas de crenças, interativo, diagnóstico e de restrições, as quais foram mensuradas com base em Abernethy e Brownell (1999), Bisbe e Malagueño (2009), Frezatti et al. (2015), Simons (1991, 1995) e Widener (2007), por meio de 37 assertivas. Para mensuração da inovação tecnológica, seguiu-se o Manual de Oslo e os estudos de Bisbe e Malagueño (2009), Bisbe e Otley (2004), Gatignon e Xuereb (1997), Miller e Friesen (1982) e Yang, Wang, Zhu e Wu (2012).

Utilizou-se escala tipo Likert de 5 pontos em todas as perguntas e foram usadas três variáveis de controle: tamanho da empresa (OCDE, 2005), setor econômico de atuação (Malerba, 2005) e controle acionário (OCDE, 2005).

Para que se pudesse avaliar a validade de face do questionário, foi realizado um pré-teste com a colaboração de dois potenciais respondentes e atuantes no mercado (um controller e um diretor administrativo e financeiro). Complementarmente, o instrumento também passou pelo crivo de especialistas da área para que se pudesse avaliar a validade de conteúdo das assertivas (Netemeyer, 
Bearden, \& Sharma, 2003). Foram consultados professores e pesquisadores da área de controle gerencial, bem como também foi buscada colaboração para revisões informais, além da criação de condições similares àquelas do estudo final. Ainda com relação à validade de conteúdo, alguns dos especialistas que participaram do pré-teste responderam cinco perguntas específicas sobre o conteúdo do questionário, o que gerou informações úteis para revisão antes de seu uso.

O instrumento de coleta de dados foi enviado para o correio eletrônico (e-mails) dos respondentes, acompanhado de uma Carta de Apresentação. As respostas obtidas constituem uma amostra de 169 empresas que foram definidas por conveniência. Alguns questionários, mesmo com seu preenchimento finalizado, precisaram ser descartados, de forma que a amostra estudada nesta pesquisa contém 164 empresas. A coleta de dados durou aproximadamente 85 dias, e foi realizada no segundo semestre de 2013. O questionário foi respondido por representantes da diretoria das empresas, reunindo gerentes de contabilidade, de controladoria, de estratégia e inovação, bem como analistas de relações com investidores, assessores da diretoria, superintendentes, entre outros diretores.

O questionário foi constituído de três blocos principais sobre os constructos tratados nesta pesquisa. Adicionalmente, um primeiro grupo de 13 questões serviu para delinear o perfil do respondente e da empresa que ele representou. Além de perguntas sobre a origem do controle acionário, tempo de atuação no país, tamanho (número de colaboradores), setor, cargo ocupado, subordinação e tempo de empresa, solicitou-se que o respondente se identificasse nominalmente, indicando inclusive seu e-mail e telefone de contato. Também foi questionado o nome da empresa. Ainda que questões dessa natureza possam gerar algum tipo de constrangimento e deixar dúvida quanto à preservação do anonimato das respostas, essa estratégia de coleta de dados mostrou-se útil para que se pudesse obter a finalização do preenchimento de questionários abandonados pelos respondentes sem que estivessem plenamente preenchidos.

Podsakoff, MacKenzie e Podsakoff (2012) discutem a definição de common method bias (CMB). Para minimizar os possíveis efeitos desse viés, bem como remédios procedimentais: (a) preservou-se o anonimato dos respondentes, para evitar a aquiescência e desejabilidade social; (b) foram utilizadas duas escalas diferentes, para aumentar a distância metodológica: (ba) de concordância; e (bb) de existência e utilização de alguns instrumentos de controle gerencial; (c) os itens foram mantidos simples e o questionário curto para aumentar a probabilidade do entrevistado responder com precisão e não de modo estilístico. Apesar desse esforço, não há garantia de que algum viés não esteja presente, o que seria eliminado apenas com o uso de medidas objetivas para a variável dependente.

Empregou-se a técnica de Modelagem de Equações Estruturais (MEE) para análise dos dados e estimação do modelo teórico desenvolvido com base na revisão da literatura. Foi utilizado o software SmartPLS 2.0.M3 (Ringle, Wende, \& Will, 2005) e a MEE foi desenvolvida com estimação por Mínimos Quadrados Parciais.

A avaliação do tamanho da amostra e do poder estatístico das análises foi realizada por meio do software G*Power 3 (Faul, Erdfelder, Lang, \& Buchner, 2007) e por recomendações de Chin e Newsted (1999), Cohen (1977) e Hair, Hult, Ringle e Sarstedt (2014). Conforme ilustrado na Figura 1, a maior quantidade de setas que chegam a uma variável latente é 7 (maior quantidade de preditores). Considerando-se 7 preditores, nível de significância de 5\%, poder estatístico de 0,8 e tamanho do efeito médio ( $\mathrm{f}^{2}=0,15$, que equivale a $\mathrm{R}^{2}=13 \%$ ), tem-se que o tamanho mínimo da amostra é 103 . Como a amostra utilizada foi de 164 empresas, é adequada para a estimação por Partial least squares path modeling (PLS-PM). As análises a posteriori (post hoc) para a amostra obtida indicam que: (a) qualquer $\mathrm{R}^{2}$ superior a $8,4 \%$ seria detectado como significante, mantendo o poder de 0,8 e nível de significância a 5\%; e (b) para o tamanho de efeito médio o poder é de 0,96 , que é bem superior ao valor de 0,8 , recomendado por Chin e Newsted (1999) e Hair et al. (2014). 


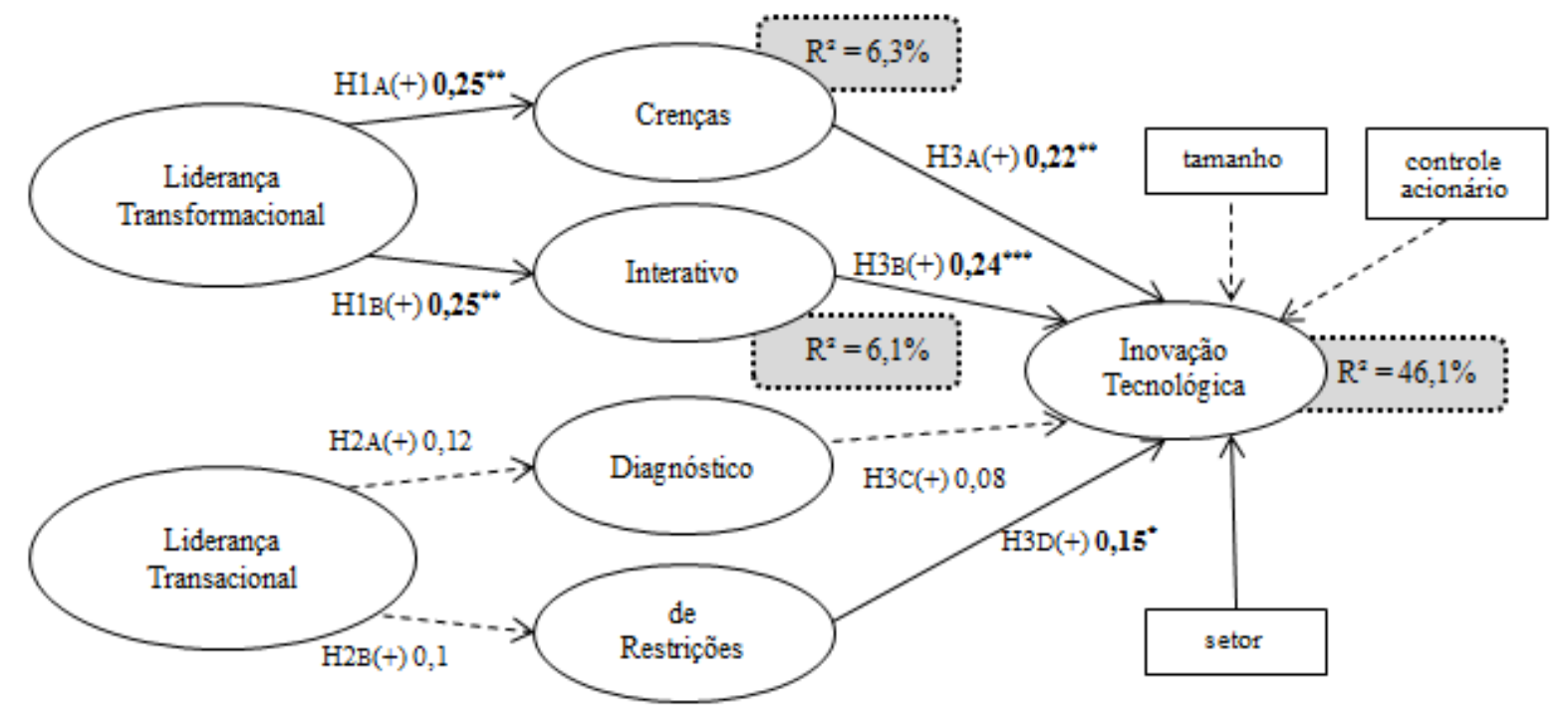

. Crenças $=$ sistema de crenças

. Interativo $=$ sistema de controle interativo

. Diagnóstico = sistema de controle diagnóstico

. de Restrições = sistema de restrições

. Setor $=$ relação de 22 setores possíveis [atacado, autoindústria, bens de capital, bens de consumo etc.]

. tamanho = número de colaboradores (até 499; entre 1.500 e 1.499; entre 1.500 e 2.499; entre 2.500 e 3.499; 3.500 ou mais)

. Controle acionário $=($ estatal, nacional, multinacional, outro $)$

Figura 1. Resultados do Modelo Estrutural

${ }^{* *} \mathrm{p}<0,01 ;{ }^{*} \mathrm{p}<0,10$; seta tracejada $=$ coeficiente não significante $(\mathrm{p}>0,10)$.

\section{Apresentação e Discussão dos Resultados}

As 164 empresas estudadas nesta pesquisa exploram 20 setores distintos. Os setores de produção agropecuária, serviços e energia respondem por $36 \%$ da amostra investigada e predominam empresas com mais de 3.500 colaboradores ( $28,7 \%$ da amostra). O controle acionário da maioria das empresas é nacional (120 organizações), existindo, ainda, 14 estatais e 30 multinacionais. $O$ tempo de atuação no Brasil é bastante homogêneo dentre as empresas pesquisadas: 91,5\% (150 organizações) atuam há mais de 10 anos no país.

\section{Avaliação do modelo de mensuração}

Todas as variáveis latentes foram modeladas de modo reflexivo (Hair, Hult, Ringle, \& Sarstedt, 2014; Jarvis, Mackenzie, \& Podsakoff, 2003) e, por este motivo, antes de se proceder à avaliação dos coeficientes estruturais, são avaliadas: validade convergente, validade discriminante e a confiabilidade dos construtos.

Para avaliação do modelo de mensuração foram analisadas a validade convergente, a validade discriminante e a confiabilidade. Inicialmente, todos os indicadores foram utilizados na mensuração dos construtos. A avaliação da validade convergente foi feita por meio da variância média extraída (AVE). Algumas variáveis latentes apresentaram AVE inferior ao mínimo recomendado por Ringle, Sarstedt, e Straub (2012), que é 0,5 : liderança transacional $(0,476)$, sistema de controle interativo $(0,4363)$ e inovação tecnológica $(0,4848)$. No caso da liderança transacional, optou-se pela manutenção de seus indicadores para não prejudicar a validade de conteúdo e a replicabilidade do estudo, tendo em vista que o instrumento utilizado está consolidado e que replicações futuras poderão apresentar melhores resultados (DeVellis, 2003; Netemeyer et al., 2003). Quanto aos constructos sistema interativo e 
inovação tecnológica, excluíram-se 2 indicadores que apresentaram as menores cargas e foi obtido um modelo ajustado.

A avaliação do modelo de mensuração ajustado indicou que, com exceção da liderança transacional, todas as variáveis latentes atingiram a AVE mínima recomendada. Quanto à confiabilidade composta (CR), todas as variáveis apresentaram valores superiores a 0,7 , o que é considerado adequado (Hair et al., 2014). A validade discriminante foi avaliada no nível dos indicadores e das variáveis latentes. Todos os indicadores apresentaram cargas fatoriais maiores em suas respectivas variáveis latentes do que em qualquer outra. Quando ao nível das variáveis latentes, a raiz quadrada da variância média extraída, indicada na Tabela 1 (diagonal, em negrito), mostrou-se superior às correlações entre todas as variáveis latentes (tanto na vertical, quanto na horizontal) (Ringle, Sarstedt, \& Straub, 2012), reforçando assim, a validade discriminante (Fornell \& Larcker, 1981; Ringle et al., 2012).

Tabela 1

Matriz de Correlações entre as Variáveis Latentes

\begin{tabular}{|c|c|c|c|c|c|c|c|}
\hline Variável Latente & 1 & 2 & 3 & 4 & 5 & 6 & 7 \\
\hline 1. Liderança Transformacional & 0,812 & & & & & & \\
\hline 2. Liderança Transacional & 0,363 & 0,690 & & & & & \\
\hline 3. Sistema de Crenças & 0,250 & 0,172 & 0,779 & & & & \\
\hline 4. Sistema Interativo & 0,247 & 0,150 & 0,530 & 0,705 & & & \\
\hline 5. Sistema Diagnóstico & 0,217 & 0,118 & 0,477 & 0,644 & 0,739 & & \\
\hline 6. Sistema de Restrições & 0,040 & 0,099 & 0,481 & 0,415 & 0,474 & 0,723 & \\
\hline 7. Inovação Tecnológica & 0,171 & 0,198 & 0,517 & 0,540 & 0,474 & 0,410 & $\mathbf{0 , 7 0 7}$ \\
\hline Média & 4,14 & 3,13 & 3,87 & 3,69 & 3,83 & 3,57 & 3,38 \\
\hline Desvio Padrão & 0,530 & 1,065 & 0,841 & 0,955 & 1,042 & 1,141 & 0,909 \\
\hline Coeficiente de Variação & $13 \%$ & $34 \%$ & $22 \%$ & $26 \%$ & $27 \%$ & $32 \%$ & $27 \%$ \\
\hline Escala Likert & A & a & $\mathrm{b}$ & $\mathrm{b}$ & $c+d$ & $\mathrm{~b}$ & $\mathrm{~b}$ \\
\hline Variância Média Extraída (AVE) & 0,659 & 0,476 & 0,607 & 0,497 & 0,546 & 0,522 & 0,500 \\
\hline Confiabilidade Composta (CR) & 0,885 & 0,722 & 0,900 & 0,866 & 0,943 & 0,896 & 0,956 \\
\hline
\end{tabular}

Nota. Correlações superiores a $|0,153|$ são significantes a 5\% (bicaudal); Correlações superiores a $|0,201|$ são significantes a $1 \%$ (bicaudal).

(a) 5, 4, 3, 2, 1 - sempre, frequentemente, às vezes, raramente, nunca. (b) 5, 4, 3, 2, 1, 0 - concordo totalmente, concordo parcialmente, nem concordo nem discordo, discordo parcialmente, discordo totalmente, não sei dizer. (c) 5, 4, 3, 2, 1, 0 bastante usado, uso incipiente de modo geral, uso incipiente em alguns pontos, está em implementação, não existe na empresa, não sei dizer. (d) 5, 4, 3, 2, 1 - muito alta, alta, média, baixa, muito baixa (intensidade de uso de medidas de desempenho).

Considerando-se a escolha de preservar a validade de conteúdo e a replicabilidade do estudo, a validade convergente, a validade discriminante e a confiabilidade indicaram uma avaliação positiva do modelo de mensuração. Desse modo, é possível afirmar que as variáveis latentes foram adequadamente mensuradas. A seguir, tem-se a avaliação do modelo estrutural.

\section{Avaliação do modelo estrutural}

Os coeficientes estruturais foram calculados pelo software SmartPLS 2.0.M3 (Ringle et al., 2005) e os valores $p$ foram estimados por bootstrap, considerando-se uma amostra de 164 casos e 1000 reamostragens, para que se pudessem obter intervalos de confiança para avaliar a significância dos coeficientes estimados. Os resultados do modelo estrutural estão ilustrados na Figura 1. As setas pontilhadas indicam coeficientes que não são significantes. 
As hipóteses que exploraram o efeito da liderança transacional sobre os sistemas de controles de restrições e diagnóstico e deste sobre a inovação tecnológica não foram validadas. Dentre as variáveis de controle inseridas no modelo, apenas o setor mostrou-se significante $(\mathrm{p}<0,01)$.

A Tabela 2 reúne as estatísticas das relações estruturais. Os coeficientes estruturais das hipóteses $2_{\mathrm{A}}$ e $2_{\mathrm{B}}$ não foram significantes e o coeficiente estrutural entre liderança transacional e sistema de controle diagnóstico e, ainda, entre liderança transacional e sistema de restrições (Tabela 1) também não atingiram significância. Apesar de o coeficiente estrutural da hipótese $3_{\mathrm{C}}$ não ter sido significante, a correlação entre o sistema de controle diagnóstico e a inovação tecnológica foi de 0,474 (p < 0,01), o que sugere que o coeficiente estrutural não significante possa ser resultante do efeito da multicolinearidade, mesmo que esse efeito seja baixo (Cohen, Cohen, Wert, \& Aiken, 2002).

Tabela 2

\section{Estatísticas das Relações Estruturais}

\begin{tabular}{lcccccc}
\hline Hipótese & $\begin{array}{c}\text { Coeficiente } \\
\text { Estrutural }\end{array}$ & $\begin{array}{c}\text { Erro } \\
\text { Padrão }\end{array}$ & Valor t & Valor p & $\mathrm{R}^{2}$ & Resultado \\
\hline $\mathrm{H}_{1 \mathrm{~A}}$ : transformacional => crenças & 0,250 & 0,0740 & 3,38 & 0,0008 & $6,3 \%$ & $\mathrm{a}$ \\
$\mathrm{H}_{1 \mathrm{~B}}$ : transformacional => interativo & 0,247 & 0,0928 & 2,67 & 0,0078 & $6,1 \%$ & $\mathrm{a}$ \\
$\mathrm{H}_{2 \mathrm{~A}}$ : transacional => diagnóstico & 0,118 & 0,1829 & 0,64 & 0,5196 & $1,4 \%$ & \\
H $\mathrm{H}_{2 \mathrm{~B}}$ : transacional => de restrições & 0,098 & 0,0938 & 1,04 & 0,2987 & $1,0 \%$ & \\
$\mathrm{H}_{3 \mathrm{~A}}$ : crenças => inovação tecnológica & 0,224 & 0,0786 & 2,86 & 0,0044 & $46,1 \%$ & $\mathrm{a}$ \\
$\mathrm{H}_{3 \mathrm{~B}}$ : interativo => inovação tecnológica & 0,237 & 0,0869 & 2,73 & 0,0064 & & $\mathrm{a}$ \\
$\mathrm{H}_{3 \mathrm{C}}$ : diagnóstico => inovação tecnológica & 0,077 & 0,0875 & 0,88 & 0,3820 & Nota 2 & \\
H $\mathrm{H}_{3 \mathrm{D}}$ : de restrições => inovação tecnológica & 0,146 & 0,0764 & 1,91 & 0,0561 & & $\mathrm{a}$ \\
Variáveis de Controle & & & & & & \\
controle acionário => inovação tecnológica & 0,039 & 0,0651 & 0,60 & 0,5512 & & \\
setor => inovação tecnológica & $-0,270$ & 0,0722 & 3,74 & 0,0002 & & \\
tamanho => inovação tecnológica & 0,040 & 0,0620 & 0,65 & 0,5143 & & \\
\hline
\end{tabular}

Nota: Fonte: Cohen, J. (1977). Statistical power analysis for the behavioral sciences (revised.). New York: Academic Press. Significâncias (valor t e p) estimadas por bootstrap com 1000 repetições e $\mathrm{n}=164$.

$\mathrm{R}^{2}$ ajustado $=43,7 \%$ - classifica valores de $\mathrm{R}^{2}$ de até $13 \%$ como efeito baixo, superiores a $13 \%$ como efeito médio e superiores a $26 \%$ como grande.

$\mathrm{a}=$ hipótese sustentada.

\section{Discussão dos resultados}

Os resultados indicam que o estilo de liderança tem baixo poder explicativo das escolhas ligadas à definição de uso do SCG, mas, por outro lado, os tipos de uso propostos por Simons (1990, 1991, 1995) têm alto poder explicativo da inovação tecnológica. Independentemente de o poder explicativo ser alto ou baixo (Cohen, 1977, classifica valores de $\mathrm{R}^{2}$ de até $13 \%$ como efeito baixo, superiores a $13 \%$ como feito médio e superiores a $26 \%$ como grande), os resultados fornecem contribuições relevantes à pesquisa em controle gerencial. De forma geral, os achados indicam que as empresas viabilizam as alavancas por meio de uma variedade de mecanismos de controle, tais como: (a) a missão e a comunicação estabelecidas pelos gestores que são usados para compartilhar os valores centrais; (b) reuniões entre gestores que fazem uso de informações do SCG para discutir mudanças e acompanhar projetos de inovação; (c) uso de planejamento estratégico, orçamento, rolling forecast, controle orçamentário, entre outros indicadores para fornecer informações gerais e asseguar o cumprimento dos objetivos; e, ainda, (d) código de conduta que indica o campo de ação. 


\section{Estilo de liderança e definição de uso do sistema de controle gerencial}

Os resultados suportam as hipóteses de que a liderança transformacional influencia positivamente o sistema de crenças $\left(\mathrm{H}_{1 \mathrm{~A}}\right)$ e o sistema interativo $\left(\mathrm{H}_{1 \mathrm{~B}}\right)$, o que corrobora a literatura (Bass, 2008; Northouse, 2009; Simons, 1990, 1991, 1995). Significa que a liderança transformacional está associada a um conjunto de crenças que define os valores básicos da organização, seu propósito e direção, além da criação de valor e das relações que são estabelecidas no ambiente de trabalho (Simons, 1995). O modelo sugere que a liderança transformacional é relevante às escolhas de controle ligadas aos sistemas de crenças (Path Coefficient = 0,2502; p < 0, 01). Assim, a inspiração que o líder promove em seus seguidores para que busquem novas oportunidades é influenciada pelo estilo transformacional. Esse achado reforça a ideia de que os colaboradores estão envolvidos com os valores da empresa quando seus líderes são transformacionais. Significa que a influência que o líder promove em seus seguidores confere significado ao sistema de crenças. Assim, ao imprimir um formato individualizado para lidar com cada um de seus subordinados e projetar uma visão otimista de futuro, o líder transformacional exibe uma forma muito particular e estimulante para comunicar o sistema de crenças à sua equipe; ele impulsiona o sistema de crenças.

Esta pesquisa também comprova que a liderança transformacional influencia o sistema interativo (Path Coefficient $=0,2472 ; \mathrm{p}<0,01$ ). Significa dizer que o perfil transformacional favorece o uso do SCG na forma interativa, sugerindo que o diálogo e o conhecimento compartilhado pelo líder de forma carismática e inspiradora geram um ambiente propício para o uso interativo. Logo, o comportamento do líder promove um ambiente favorável para que as informações geradas pelo SCG sejam revistas, questionadas e discutidas. A forma de agir do líder transformacional e, ainda, o modo como ele se comunica com seus subordinados sugere que as informações contábeis são usadas como um ponto de partida para provocar diálogo e debate sobre o trabalho, de forma geral, e sobre as incertezas estratégicas, pois esta é a proposta do sistema interativo (Simons, 1995). Ademais, o líder transformacional tende a usar tais informações como um mecanismo para treinar e ajudar seus subordinados a melhorar seus desempenhos, o que é convergente com os achados de Jansen (2011).

Quanto à liderança transacional, não foram encontradas evidências que sustentem as hipóteses de que liderança transacional influencia positivamente o sistema diagnóstico $\left(\mathrm{H}_{2 \mathrm{~A}}\right)$ e o sistema de restrições $\left(\mathbf{H}_{2 \mathrm{~B}}\right)$. Era esperado que os líderes transacionais fizessem uso desses sistemas como um recurso para externar suas expectativas aos subordinados e permitir que decidissem por si mesmos, como atendê-las para chegar ao nível de desempenho desejado. Possivelmente as hipóteses $2_{\mathrm{A}}$ e $2_{\mathrm{B}}$ não tenham sido confirmadas em virtude de características da amostra estudada (convenientemente selecionada), mas ainda assim, esses achados surpreendem. Ao investigarem os determinantes do estilo de uso do sistema de controle gerencial, Harlez e Malagueño (in press) comprovaram que o uso diagnóstico é regido pelo profissionalismo dos gestores, sugerindo, assim, que características comportamentais dos líderes afetam esse tipo de uso.

\section{Definição de uso do sistema de controle gerencial e inovação tecnológica}

Conforme esperado, os achados suportam a hipótese de que a definição de uso do sistema de crenças influencia positivamente a inovação tecnológica $\left(\mathbf{H}_{3 \mathrm{~A}}\right)$. Significa que, nas empresas pesquisadas, o esforço de formatar um sistema amplo no sentido de indicar valores que serão centrais à organização por um longo período de tempo e, ao mesmo tempo, atuais, no sentido de estarem conectados com as demandas presentes, tem um efeito positivo sobre a inovação tecnológica (Path Coefficient $=0,2243 ; \mathrm{p}<0,01$ ). Assim, ao promover o comprometimento dos colaboradores com os objetivos da organização e inspirar a busca por novas oportunidades, o sistema de crenças colabora com o processo de inovação. Esse achado é relevante, pois indica um caminho para as organizações que eventualmente têm encontrado dificuldades em incorporar processos de inovação tecnológica em seus modelos de gestão. Nesse sentido, Arjaliès e Mundy (2013) destacam que, ao fornecer um senso de estabilidade e continuidade, o sistema de crenças pode habilitar a realização de mudanças na organização se os gestores o utilizarem para introduzir novas prioridades e valores. 
A confirmação da hipótese 3 A sugere que as empresas podem estar incorporando informações sobre inovação em produtos e processos nos valores e propósitos que são declarados interna e/ou externamente. Também é relevante considerar que o sistema de crenças é um instrumento de comunicação eficiente e silencioso, pois qualquer esforço empreendido para inspirar os colaboradores a buscar novas oportunidades à empresa através de associação entre inovação tecnológica e valores da organização representa um uso do sistema de crenças. Assim, os achados confirmam que canais formais e informais de comunicação podem ser usados para reforçar as orientações estratégicas de empresas que investem em atividades de inovação e precisam lidar com crescente incerteza e complexidade em suas ações. Dessa forma, o uso do sistema de crenças colabora para promover coerência organizacional no que diz respeito à inovação tecnológica.

A hipótese de que a definição de uso do sistema de controle interativo influencia positivamente a inovação tecnológica $\left(\mathbf{H}_{3 \mathbf{B}}\right)$ também foi confirmada. Esse achado indica que o uso interativo do SCG tem papel relevante no desenvolvimento de ações que permitam articular estratégias correntes e emergentes no processo de inovação tecnológica (Path Coefficient = 0,2374; p < 0,01). Resultados similares foram obtidos por Arjaliès e Mundy (2013), que comprovaram que a realização de discussões formais com departamentos operacionais proporciona ideias relevantes vindas de outras áreas do negócio para os gestores. As autoras constataram que o envolvimento ativo de membros externos à organização em discussões formais promove o uso interativo do SCG. Esse achado também é consistente com Widener (2007), que encontrou evidências de que o sistema de controle interativo é usado para fazer uma varredura no ambiente externo. Dunk (2011) demonstrou que, ao ser usado a partir de uma perspectiva interativa, o orçamento facilita a inovação de produtos e colabora para o desempenho financeiro da organização, o que não se confirmou quando seu uso se dá na forma diagnóstica. Sánchez, López-Valeiras, Rodríguez-González e Feliu (2013) comprovaram a hipótese de que o uso interativo do SCG impacta positivamente três tipos de desempenho da capacidade inovativa: inovação de produtos, inovação de processos e inovação organizacional. Os achados de Chong e Mahama (2014) também corroboram a hipótese $3_{\mathrm{B}}$. Os autores confirmaram que o uso interativo do orçamento em empresas de inovação melhora a eficácia de suas equipes. Em síntese, os achados indicam que o uso interativo do SCG serve como guia para alcançar a inovação.

A hipótese de que a definição de uso do sistema de controle diagnóstico influencia positivamente a inovação tecnológica $\left(\mathbf{H}_{3 \mathbf{C}}\right)$ não foi confirmada (Path Coefficient $=0,0765 ; \mathrm{p}=$ 0,3820). Esperava-se que, ao proporcionar o acompanhamento de variáveis críticas de desempenho e auxiliar no monitoramento e coordenação das estratégias (Simons, 1995), o sistema diagnóstico proporcionasse condições que contribuíssem para as atividades de inovação. A não comprovação da $\mathrm{H}_{3 \mathrm{C}}$ indica que o conjunto de rotinas e procedimentos que é estruturado pelo SCG para colocar a estratégica pretendida em prática não colabora para a inovação tecnológica nas empresas pesquisadas. Similarmente aos achados deste estudo, Malagueño e Bisbe (2010) não comprovaram a hipótese de que o sistema diagnóstico influencia positivamente a inovação. Isso significa que o desenvolvimento de indicadores de inovação ainda representa uma lacuna no SCG de muitas empresas brasileiras, e sugere que as organizações têm dificuldade de monitorar e avaliar esforços de inovação.

Considerando que uma das principais tarefas do sistema diagnóstico é identificar desvios em relação à estratégia pretendida e articular ações corretivas, a ausência e/ou carência de objetivos de inovação pode então minar a capacidade que tal sistema tem de influenciar positivamente a inovação. $\mathrm{O}$ fato de o uso diagnóstico não estar contribuindo para inovação nas empresas estudadas pode significar que estejam enfrentando dificuldades em fornecer indicadores de inovação que sejam confiáveis e também relevantes à gestão da organização como um todo.

A última hipótese proposta, de que a definição de uso do sistema de restrições influencia positivamente a inovação tecnológica $\left(\mathbf{H}_{3 \mathrm{D}}\right)$ foi confirmada. Significa dizer que os limites estratégicos estabelecidos pela organização impulsionam a inovação tecnológica (Path Coefficient $=0,1462 ; \mathrm{p}<$ 0,10). Assim, é possível supor que o código de conduta mantido pelas empresas permite que a criatividade seja manifestada, e que sejam realizadas propostas que contribuam para criação de novos produtos e/ou processos, ou ainda, que gerem melhorias em produtos e/ou processos já existentes. Esse achado é relevante, pois esse tipo de orientação auxilia na identificação de oportunidades relacionadas 
com a estratégia perseguida pela organização. Significa que o sistema de restrições relembra aos colaboradores suas responsabilidades e delimita restrições em volta do sistema de crenças para inspirálos a inovar e buscar novas oportunidades (Arjaliès \& Mundy, 2013).

Em resumo, a confirmação das hipóteses $3_{\mathrm{A}}, 3_{\mathrm{B}}$ e $3_{\mathrm{D}}$ indica que a inovação tem sido considerada um elemento estratégico no modelo de negócios das empresas estudadas. Significa que o uso do SCG nas formas de sistemas de crenças, interativo e de restrições associado aos esforços de inovação tecnológica tem proporcionado a renovação estratégica.

\section{Conclusões}

Esta investigação explorou o estilo de liderança como um antecedente da definição de uso do SCG e o papel de seus diferentes tipos de uso na inovação tecnológica. O uso do modelo de Simons (1990, 1991, 1995), considerando as quatro alavancas de controle, representa uma contribuição desta pesquisa, pois a maioria dos estudos explora apenas os usos interativo e/ou diagnóstico. Duas hipóteses envolvendo o sistema de crenças e uma envolvendo o sistema de restrições foram validadas, gerando evidências acerca de duas alavancas de controle que não têm recebido tanta atenção.

Confirmou-se que o uso dos sistemas de crenças e interativo é dependente do estilo de liderança transformacional. A liderança transformacional foi comprovada como um antecedente do uso interativo do SCG e também do sistema de crenças, demonstrando que o líder transformacional confere significado ao sistema de crenças e seu comportamento cria condições para que as informações geradas pelo SCG sejam revistas, questionadas e discutidas entre os membros da organização, em um clima favorável para identificação de estratégias emergentes. Verificou-se que os gestores são atores internos relevantes que impactam a implementação de novas práticas, processos e estruturas. Entender o efeito do estilo de liderança nas escolhas de controle é relevante porque beneficia aquele que é responsável pela seleção e pelo desenvolvimento da gestão, e ainda pelo fato de ser muitas vezes negligenciado quando escolhas de controle são discutidas (Abernethy et al., 2010).

Este estudo também fornece importantes insights acerca de estruturas e processos por meio dos quais a inovação é promovida nas organizações. Os achados indicam que as empresas que buscam inovar em seus produtos e processos devem investir: (a) na comunicação de valores e objetivos relacionados à inovação; (b) em discussões que envolvam diferentes áreas e membros do negócio, considerando inclusive a possibilidade de interagir com agentes externos à empresa; e, ainda, (c) no estabelecimento de limites que especifiquem um campo de ação para os colaboradores da organização, fornecendo foco e gerando condições para que as ações pretendidas sejam de fato desenvolvidas.

Os achados também confirmam que o setor influencia a inovação tecnológica. Assim, esta pesquisa expande o conhecimento sobre controle gerencial ao proporcionar achados que indicam a forma de uso do SCG por meio do qual as organizações conseguem promover a inovação e obter a renovação estratégica (Arjaliès \& Mundy, 2013). Desse modo, os resultados do estudo podem encorajar novas formas de uso ao SCG para proporcionar condições para que a inovação seja bem sucedida.

Quanto às expectativas que não foram confirmadas, os achados não suportam a hipótese de que a liderança transacional seja um antecedente da definição de uso dos sistemas diagnóstico e de restrições $\left(\mathrm{H}_{2 \mathrm{~A}}\right.$ e $\left.\mathrm{H}_{2 \mathrm{~B}}\right)$, o que era esperado pelo fato de suas propostas serem condizentes com uma perspectiva de gestão mais rígida. Acredita-se que novos aprofundamentos sobre a relação entre liderança transacional e o uso do sistema de controle gerencial possam gerar contribuições relevantes para esse campo de pesquisa e atribui-se a não confirmação das hipóteses $2_{\mathrm{A}} \mathrm{e} 2_{\mathrm{B}}$ a características da amostra e a mensuração das variáveis estudadas.

Também não foram encontradas evidências que suportem a hipótese de que a definição de uso do sistema de controle diagnóstico influencie positivamente a inovação tecnológica $\left(\mathrm{H}_{3 \mathrm{C}}\right)$. É possível que esse resultado tenha sido obtido em virtude de especificidades das empresas estudadas. Esforços do 
governo brasileiro indicam que as organizações exibem certa carência na mensuração de atividades de inovação. Assim, a não comprovação da $\mathrm{H}_{3 \mathrm{C}}$ representa um importante alerta às empresas que assumem o desafio de incorporar inovação tecnológica à sua estratégia, pois é possível que o uso diagnóstico esteja assumindo uma dimensão distinta daquela desejada para proporcionar avanços em termos de inovação. Como o uso diagnóstico do SCG propõe a identificação de desvios em relação à estratégia pretendida, a dificuldade de formalização de metas e objetivos tende a minimizar as potencialidades que tal sistema tem para colaborar com a inovação tecnológica.

A interpretação dos resultados deste estudo deve levar em conta limitações da amostra estudada, pois foi obtida por conveniência, portanto, não são generalizáveis. Além disso, os executivos tendem a responder as questões considerando o estado da arte do tema, o que pode não representar a realidade de organização; por isso, o ideal seria coletar dados objetivos e longitudinais, o que foi inacessível aos pesquisadores. Em adição, considerou-se que o estilo de liderança do respondente representa a organização à qual ele pertence.

Futuras pesquisas poderiam empregar outras metodologias, tais como estudos de casos longitudinais. Destaca-se também que novas investigações poderiam reunir evidências também provenientes de subordinados dos líderes, bem como partir de um modelo que inclua variáveis mensuradas objetivamente de modo a evitar respostas enviesadas. Por fim, considerando que a inovação tecnológica representa um desejo de muitas organizações, sugere-se a realização de estudos que explorem as políticas de incentivo e recompensas que têm sido instituídas para promovê-la, bem como os possíveis efeitos da cultura de inovação (Bruno-Faria \& Fonseca, 2014) como antecedente do estilo de liderança, e da aprendizagem organizacional (Alsalami et al., 2014) como mediadora da relação entre liderança transformacional e inovação.

\section{Referências}

Abernethy, M. A., Bouwens, J., \& Lent, L. van (2010). Leadership and control system design. Management Accounting Research, 21(1), 2-16. doi: 10.1016/j.mar.2009.10.002

Abernethy, M. A., \& Brownell, P. (1999). The role of budgets in organizations facing strategic change: an exploratory study. Accounting, Organizations and Society, 24(3), 189-204. doi: $10.1016 / \mathrm{S} 0361-3682(98) 00059-2$

Alsalami, E., Behery, M., \& Abdullah, S. (2014). Transformational leadership and its effects on organizational learning and innovation: evidence from Dubai. The Journal of Applied Management and Entrepreneurship, 19(4), 61-82.

Antonakis, J., Avolio, B. J., \& Sivasubramaniam, N. (2003). Context and leadership: an examination of the nine-factor full-range leadership theory using the multifactor leadership questionnaire. The Leadership Quarterly, 14(3), 261-295. doi: 10.1016/S1048-843(03)00030-4

Arjaliès, D.-L., \& Mundy, J. (2013). The use of management control systems to manage CSR strategy: a levers of control perspective. Management Accounting Research, 24(4), 284-300. doi: 10.1016/j.mar.2013.06.003

Armbruster, H., Bikfalvi, A., Kinkel, S., \& Lay, G. (2008). Organizational innovation: The challenge of measuring non-technical innovation in large-scale surveys. Technovation, 28(10), 644-657. doi: 10.1016/j.technovation.2008.03.003

Bass, B. M. (2008). The bass handbook of leadership: theory, research \& managerial applications (4th ed.). New York: Free Press.

Bass, B. M., \& Riggio, R. E. (2005). Transformational leadership (2nd ed.). New York: Psychology Press. 
Bisbe, J., \& Malagueño, R. (2009). The choice of interactive control systems under different innovation management modes. European Accounting Review, 18(2), 371-405. doi: $10.1080 / 09638180902863803$

Bisbe, J., \& Otley, D. (2004). The effects of the interactive use of management control systems on product innovation. Accounting, Organizations and Society, 29(8), 709-737. doi: 10.1016/j.aos.2003.10.010

Bruno-Faria, M. F., \& Fonseca, M. V. A. (2014). Cultura de inovação: conceitos e modelos teóricos. Revista de Administração Contemporânea, 18(4), 372-396. Recuperado de http://www.scielo.br/pdf/rac/v18n4/1415-6555-rac-18-04-00372.pdf. doi: 10.1590/19827849rac20141025

Calaça, P. A., \& Vizeu, F. (2015). Revisitando a perspectiva de James MacGregor Burns: qual é a ideia por trás do conceito de liderança transformacional? Cadernos EBAPE.BR, 13(1), 121-135. Recuperado de http://www.scielo.br/pdf/cebape/v13n1/1679-3951-cebape-13-01-00121.pdf. doi: $10.1590 / 1679-395111016$

Chin, W. W., \& Newsted, P. R. (1999). Structural equation modeling analysis with small samples using partial least squares. In R. H. Hoyle (Ed.), Statistical strategies for small sample research (pp. 307-341). Thousand Oaks, CA: Sage Publications.

Chong, K. M., \& Mahama, H. (2014). The impact of interactive and diagnostic uses of budgets on team effectiveness. Management Accounting Research, 25(3), 206-222. doi: 10.1016/j.mar.2013.10.008

Cohen, J. (1977). Statistical power analysis for the behavioral sciences (Revised). New York: Academic Press.

Cohen, J., Cohen, P., Wert, S. G., \& Aiken, L. S. (2002). Applied multiple regression/correlation analysis for the behavioral sciences (3rd ed.). New Jersey: Routledge.

Cummings, L. (1965). Organizational climates for creativity. Academy of Management Journal, 8(3), 220-227. doi: $10.2307 / 254790$

Damanpour, F. (1991). Organizational innovation: a meta-analysis of effects of determinants and moderators. Academy of Management Journal, 34(3), 555-590. doi: 10.2307/256406

Damanpour, F., Szabat, K. A., \& Evan, W. M. (1989). The relationship between types of innovation and organizational performance. Journal of Management Studies, 26(6), 587-602. doi: 10.1111/j.1467-6486.1989.tb00746.x

DeVellis, R. F. (2003). Scale development: theory and applications (2nd ed.). Thousand Oaks: Sage Publications, Inc.

Dunk, A. S. (2011). Product innovation, budgetary control, and the financial performance of firms. The British Accounting Review, 43(2), 102-111. doi: 10.1016/j.bar.2011.02.004

Faul, F., Erdfelder, E., Lang, A.-G., \& Buchner, A. (2007). G*Power 3: a flexible statistical power analysis program for the social, behavioral, and biomedical sciences. Behavior Research Methods, 39(2), 175-191. doi: 10.3758/BF03193146

Fornell, C., \& Larcker, D. (1981). Evaluating structural equation models with unobservable variables and measurement error. Journal of Marketing Research, 18(1), 39-50. doi: 10.2307/3151312

Freeman, C. (1995). The 'National System of Innovation' in historical perspective. Cambridge Journal of Economics, 19(1), 5-24. 
Frezatti, F., Bido, D. S. de, Cruz, A. P. C. da, \& Machado, M. J. C. (2014). O papel do Balanced Scorecard na gestão da inovação. Revista de Administração de Empresas, 54(4), 128-153. doi: $10.1590 / \mathrm{S} 0034-759020140404$

Frezatti, F., Bido, D. S. de, Cruz, A. P. C. da, \& Machado, M. J. C. (2015). The structure of artefacts of management control in the innovation processo: does exist association with the strategic profile? Brazilian Business Review, 12(1), 128-153. doi: 10.15728/bbr.2015.12.6

García-Morales, V. J., Jiménez-Barrionuevo, M. M., \& Gutiérrez-Gutiérrez, L. (2012). Transformational leadership influence on organizational performance through organizational learning and innovation. Journal of Business Research, 65(7), 1040-1050. doi: 10.1016/j.jbusres.2011.03.005

Gatignon, H., \& Xuereb, J.-M. (1997). Strategic orientation of the firm and new product performance. Journal of Marketing Research, 34(1), 77-90. doi: 10.2307/3152066

Gopalakrishnan, S., \& Damanpour, F. (1997). A review of innovation research in economics, sociology and technology management. Omega, 25(1), 15-28. doi: 10.1016/S0305-0483(96)00043-6

Gumusluoglu, L., \& Ilsev, A. (2009). Transformational leadership, creativity, and organizational innovation. Journal of Business Research, 62(4), 461-473. doi: 10.1016/j.jbusres.2007.07.032

Hair, J. F., Jr., Hult, G. T. M., Ringle, C. M., \& Sarstedt, M. (2014). A primer on partial least squares structural equation modeling (PLS-SEM). Thousand Oaks, CA: Sage Publications.

Harlez, Y., \& Malagueño, R. (in press). Examining the joint effects of strategic priorities, use of management control systems, and personal background on hospital performance. Management Accounting Research. doi:10.1016/j.mar.2015.07.001

Henri, J.-F. (2006). Management control systems and strategy: a resource-based perspective. Accounting, Organizations and Society, 31(6), 529-558. doi: 10.1016/j.aos.2005.07.001

Howell, J. M., \& Avolio, B. J. (1993). Transformational leadership, transactional leadership, locus of control, and support for innovation: key predictors of consolidated-business-unit performance. Journal of Applied Psychology, 78(6), 891-902. doi: 10.1037/0021-9010.78.6.891

Hu, J., Wang, Z., Liden, R. C., \& Sun, J. (2012). The influence of leader core self-evaluation on follower reports of transformational leadership. The Leadership Quarterly, 23(5), 860-868. doi: 10.1016/j.leaqua.2012.05.004

Jansen, E. P. (2011). The effect of leadership style on the information receivers' reaction to management accounting change. Management Accounting Research, 22(2), 105-124. doi: 10.1016/j.mar.2010.10.001

Jarvis, C. B., Mackenzie, S. B., \& Podsakoff, P. M. (2003). A critical review of construct indicators and measurement model misspecification in marketing and consumer research. Journal of Consumer Research, 30(2), 199-218. doi: 10.1086/376806

Malagueño, R., \& Bisbe, J. (2010). The role of management accounting and control systems as antecedents of organizational creativity and innovation capabilities [Working Paper]. Social Science Research Network, Norwick, UK. Retrieved from http://dx.doi.org/10.2139/ssrn.1720989

Malerba, F. (2005). How and why innovation differs across sectors. In J. Fagerberg, D. C. Mowery, \& R. R. Nelson (Eds.), The Oxford handbook of innovation. Oxford: Oxford University Press.

Miller, D., \& Friesen, P. H. (1982). Innovation in conservative and entrepreneurial firms: two models of strategic momentum. Strategic Management Journal, 3(1), 1-25. doi: 10.1002/smj.4250030102 
Netemeyer, R. G., Bearden, W. O., \& Sharma, S. (2003). Scaling procedures: issues and applications. Thousand Oaks, CA: Sage Publications.

Nisiyama, E. K., \& Oyadomari, J. C. T. (2012). Sistemas de controle gerencial e o processo de inovação. Revista de Administração e Inovação, 9(1), 105-126. doi: 10.5773/rai.v1i1.634

Northouse, P. G. (2009). Leadership: theory and practice (5th ed.). Los Angeles: Sage Publications.

Organização para a Cooperação Econômica e Desenvolvimento. (2005). Manual de Oslo: diretrizes para coleta e interpretação de dados sobre inovação (3rd ed.). Rio de Janeiro: Autor.

Otley, D. (1994). Management control in contemporary organizations: towards a wider framework. Management Accounting Research, 5(3/4), 289-299. doi: 10.1006/mare.1994.1018

Oyadomari, J. C. T., Cardoso, R. L., Silva, B. O. T. S., \& Perez, G. (2010). Sistemas de controle gerencial: estudo de caso comparativo em empresas inovadoras no Brasil. Revista Universo Contábil, 6(4), 21-34. doi: 10.4270/ruc.2010429

Podsakoff, P. M., MacKenzie, S. B., \& Podsakoff, N. P. (2012). Sources of method bias in social science research and recommendations on how to control it. Annual Review of Psychology, 63, 539-569. doi: 10.1146/annurev-psych-120710-100452

Ringle, C. M., Sarstedt, M., \& Straub, D. W. (2012). A critical look at the use of PLS-SEM in MIS Quarterly. MIS Quarterly, 36(1), iii-xiv.

Ringle, C. M., Wende, S., \& Will, A. (2005). SmartPLS (versão 2.0 M3) [Software]. Germany: University of Hamburg. Retrieved from https://www.smartpls.com/smartpls2

Rogers, E. M. (1995). Diffusion of innovations. New York: The Free Press.

Sánchez, M. B. G., López-Valeiras, E., Rodríguez-González, E., \& Feliu, V. R. (2013, May). Effect of interactive use of management control systems on innovative and financial performance. Proceedings of Annual Congress of the European Accounting Association, Paris, France, 36.

Simons, R. (1990). The role of management control systems in creating competitive advantage: new perspectives. Accounting, Organizations and Society, 15(1/2), 127-143. doi: 10.1016/03613682(90)90018-P

Simons, R. (1991). Strategic orientation and top management attention to control systems. Strategic Management Journal, 12(1), 49-62. doi: 10.1002/smj.4250120105

Simons, R. (1995). Levers of control: how managers use innovative control systems to drive strategic renewal. Boston: Harvard Business Press.

Souza, J. C., \& Bruno-Faria, M. F. de (2013). Processo de inovação no contexto organizacional: uma análise de facilitadores e dificultadores. Brazilian Business Review, 10(3), 113-136. doi: $10.15728 / \mathrm{bbr} .2013 .10 .3 .5$

Vaccaro, I. G., Jansen, J. J. P., Bosch, F. A. J. van den, \& Volberda, H. W. (2012). Management innovation and leadership: the moderating role of organizational size. Journal of Management Studies, 49(1), 28-51. doi:10.1111/j.1467-6486.2010.00976.x

Van de Ven, A. H. (1986). Central problems in the management of innovation. Management Science, 32(5), 590-607. doi: 10.1287/mnsc.32.5.590

Vizeu, F. (2011). Uma aproximação entre liderança transformacional e teoria da ação comunicativa. Revista de Administração Mackenzie, 12(1), 53-81. doi: 10.1590/S1678-69712011000100003 
West, M., \& Anderson, N. (1996). Innovation in top management teams. Journal of Applied Psychology, 81(6), 680-693. doi: 10.1037/0021-9010.81.6.680

Widener, S. K. (2007). An empirical analysis of the levers of control framework. Accounting, Organizations and Society, 32(7/8), 757-788. doi: 10.1016/j.aos.2007.01.001

Yang, Y., Wang, Q., Zhu, H., \& Wu, G. (2012). What are the effective strategic orientations for new product success under different environments? An empirical study of Chinese businesses. Journal of Product Innovation Management, 29(2), 166-179. doi: 10.1111/j.1540-5885.2011.00900.x

\section{Dados dos Autores}

Ana Paula Capuano da Cruz

Av. Itália, km 8, Campus Carreiros, 96201-900, Rio Grande, RS, Brasil. E-mail: anapaulacapuanocruz@ hotmail.com

Fábio Frezatti

Av. Prof. Luciano Gualberto, 908, Cidade Universitária, 04015-012, São Paulo, SP, Brasil. E-mail: frezatti@ usp.br

Diógenes de Souza Bido

Rua da Consolação, 930, Consolação, 01302-907, São Paulo, SP, Brasil. E-mail: diogenesbido@yahoo.com.br, dsbido@gmail.com 


\section{APÊNDICE}

\begin{tabular}{|l|l|}
\hline BLOCO 1. ESTILO DE LIDERANÇA $(*)$ & E
\end{tabular}

\section{BLOCO 2. SISTEMA DE CONTROLE}

Como prática, na organização:

existem estratégias de inovação formalizadas.

existem estratégias de inovação informais.

\begin{tabular}{ll}
\hline Como prática, na sua organização: & E \\
\hline a missão da organização comunica claramente os valores centrais da empresa. & b \\
os principais gestores comunicam os valores centrais da empresa. & b \\
o grupo de colaboradores conhece/é ciente dos valores fundamentais da empresa. & b \\
a missão da empresa inspira o grupo de colaboradores. & b \\
$\begin{array}{l}\text { a missão da empresa tem um direcionamento claro em relação ao comportamento que se espera diante da b } \\
\text { inovação. }\end{array}$ & b \\
na prática, as ações do dia a dia destoam muito da missão da empresa. &
\end{tabular}

Entenda o código de conduta como as diretrizes (formais ou informais) acerca das ações na empresa (o que fazer/o que não fazer/como fazer). Isso também pode existir na sua empresa como limite de alçada. As afirmações dizem respeito ao seu comportamento e ao de toda a equipe, de modo geral. Como prática na sua organização:

há um código de conduta para definir o comportamento considerado adequado.

o código de conduta informa sobre os comportamentos que estão fora dos limites estabelecidos pela ${ }_{b}$ organização.

há um sistema que alerta sobre os riscos que devem ser evitados.

o grupo de colaboradores conhece (tem ciência) o código de conduta da empresa.

o cumprimento do código de conduta é monitorado.

quem não cumpre o código de conduta é punido de alguma forma.

apesar de haver espaço para manifestação de criatividade individual, o código de conduta limita as b propostas de algo novo/melhor.

não sei exatamente tudo o que devo fazer, mas tenho clareza do que não devo fazer.

os colaboradores são estimulados a inovar e, de modo geral, têm autonomia para iniciar os primeiros esforços de inovação, mas a decisão de quando começar a gastar não lhes compete - cabe à alta b administração.

\begin{tabular}{ll}
\hline Indique a intensidade de uso dos instrumentos de controle/indicadores em sua empresa: & $\mathrm{E}$ \\
\hline planejamento estratégico formalizado & $\mathrm{c}$ \\
orçamento anual & $\mathrm{c}$ \\
o orçamento está alinhado com o planejamento estratégico e decorre dele. & $\mathrm{c}$ \\
rolling forecast (projeções que visam proporcionar resultados financeiros). & $\mathrm{c}$ \\
capital budget (plano de projetos de investimento) & $\mathrm{c}$
\end{tabular}


controle orçamentário (relatório e discussão de resultados - previsto $X$ realizado)

remuneração variável para os executivos da empresa

as metas vinculadas à remuneração variável estão definidas no orçamento

o desempenho individual explicitado pelo controle orçamentário impacta a remuneração variável do executivo.

\begin{tabular}{lc}
\hline Indique com qual intensidade as medidas de desempenho do sistema de controle permitem: & E \\
\hline habilitar discussão em reuniões da gerência, subordinados e pares. & d \\
habilitar desafio contínuo e debater dados fundamentais, suposições e planos da ação. & d \\
fornecer uma visão comum da organização. & d \\
unificar/alinhar/dar um foco comum à organização. & d \\
desenvolver um vocabulário comum na organização. & d
\end{tabular}

\section{Como prática, na sua organização:}

costuma usar as informações dos instrumentos de controle para questionar e discutir sobre decisões e ações da sua unidade/setor.

o processo de controle de modo geral (inclusive discussão da inovação) é contínuo e exige atenção regular b e frequente dos gestores em todos os níveis.

há grande interação entre a alta gerência e os gerentes de departamento/unidade no processo de controle. b utiliza-se o sistema de controle para discutir mudanças com superiores, pares e subordinados. b a alta administração dispensa pouca atenção ao sistema de controle (inclusive sobre inovação). b a alta administração depende fortemente de especialistas para elaboração e interpretação de informações $b$ do sistema de controle.

os gestores envolvem-se pouco frequentemente ou em caráter excepcional com o sistema de controle. b os projetos de inovação são acompanhados após a implementação.

\section{BLOCO 3. INOVAÇÃO}

Comparativamente aos concorrentes, a organização:

assume a liderança no uso de tecnologias sofisticadas para o desenvolvimento de novos produtos e $b$ processos.

é mais agressiva em pesquisa e desenvolvimento.

possui melhores métodos industriais.

possui mais/melhor conhecimento competitivo.

oferece produtos e processos novos mais ambiciosos/agressivos.

Como prática, sua organização:

deseja e tem capacidade de construir e comercializar avanços tecnológicos.

é muito proativa no desenvolvimento de novas tecnologias.

sempre busca desenvolver produtos novos com o que há de mais novo em tecnologia.

possui forte estratégia de proteção da inovação (Ex.: patentes, registros de design, marcas registradas, direitos autorais, acordos confidenciais e segredos comerciais, complexidade do design de produtos, b vantagens de tempo sobre os concorrentes etc.).

desenvolve uma ampla e forte rede de relacionamentos, com fornecedores de equipamentos tecnológicos. b 
sempre está entre as primeiras empresas a usar uma nova tecnologia para desenvolver um novo produto ${ }_{b}$ ou processo.

desenvolve diferentes produtos e processos com tecnologia muito similar

oferece diferentes produtos e processos, mas eles têm mercados muito similares em termos de estratégia $\mathrm{b}$ de marketing, tipos de clientes, preços etc.

\begin{tabular}{lc}
\hline Considerando o histórico dos últimos três anos na sua organização: & E \\
\hline verifica-se o lançamento/uso de produtos e processos novos com acentuada frequência. & $\mathrm{b}$ \\
verificam-se modificações de produtos e processos já existentes com acentuada frequência. & $\mathrm{b}$ \\
$\begin{array}{l}\text { verifica-se o pioneirismo no lançamento/uso de novos produtos e processos com acentuada frequência. } \\
\begin{array}{l}\text { a percentagem de produtos e processos novos ofertados/desenvolvidos é significativamente maior do que } \\
\text { a média ofertada/desenvolvida pela concorrência. }\end{array}\end{array}$ \\
\hline
\end{tabular}

Os novos produtos e processos ofertados/usados pela organização, em sua maioria:

$\mathrm{E}$

exibem uma pequena melhora na tecnologia anterior/atual.

mudam as condições de mercado.

representam as primeiras aplicações de um avanço tecnológico.

imprimem uma mudança revolucionária em termos de tecnologia.

incorporam um grande corpo de conhecimento tecnológico.

mudam a natureza da competição. ,

西 ,

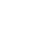

E

\section{As etapas científicas, tecnológicas, organizacionais, financeiras e comerciais que conduzem ou pretendem conduzir à implementação de inovação representam atividades de inovação (AI). Como $\mathrm{E}$ prática, na sua organização:}

as AI têm sido abandonadas antes da implementação da inovação.

as AI têm resultado na implementação de inovação (embora não necessariamente bem-sucedida b comercialmente).

as AI têm resultado em novos produtos e processos bem sucedidos. $\quad$ b

o valor que o mercado atribui aos novos produtos e processos é substantivo. b

novos produtos e processos geram um lucro considerável à organização.

Nota. (a) =1, 2, 3, 4, 5 = Nunca, raramente, às vezes, frequentemente, sempre; (b) = 0, 1, 2, 3, 4, 5 = Não sei dizer; Discordo totalmente; Discordo Parcialmente; Nem concordo, nem discordo; Concordo Parcialmente; Concordo Totalmente; $(\mathrm{c})=0,1$, $2,3,4,5$ = Não sei dizer, Não existe na empresa, Está em implementação, Uso incipiente apenas em alguns pontos, Uso incipiente de modo geral, Bastante Usado.

* Conforme determinação da Mind Garden. Inc., não é permitido reproduzir todas as assertivas do Multifactor Leadership Questionnaire que foram utilizadas neste estudo. Desse modo, optou-se por não fazer indicações dessa natureza. 